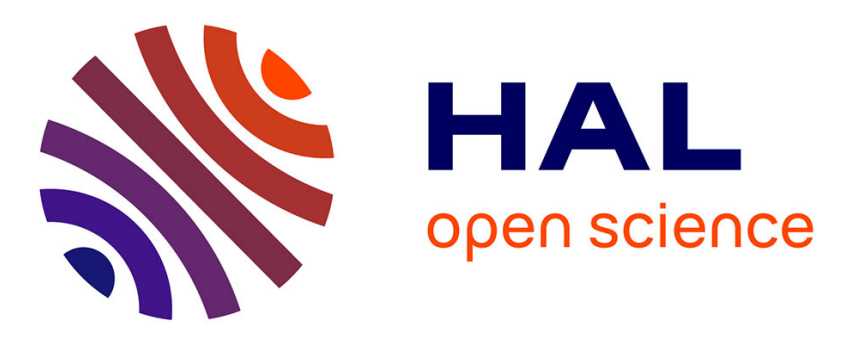

\title{
Genomic and archaeological evidence suggest a dual origin of domestic dogs
}

Laurent A. F. Frantz, Victoria E. Mullin, Maud Pionnier-Capitan, Ophélie

Lebrasseur, Morgane Ollivier, Angela Perri, Anna Linderholm, Valeria Mattiangeli, Matthew D. Teasdale, Evangelos A. Dimopoulos, et al.

\section{To cite this version:}

Laurent A. F. Frantz, Victoria E. Mullin, Maud Pionnier-Capitan, Ophélie Lebrasseur, Morgane Ollivier, et al.. Genomic and archaeological evidence suggest a dual origin of domestic dogs. Science, 2016, 352 (6290), pp.1228-1231. 10.1126/science.aaf3161 . hal-01326370

\section{HAL Id: hal-01326370 https://hal-univ-rennes1.archives-ouvertes.fr/hal-01326370}

Submitted on 21 Jul 2016

HAL is a multi-disciplinary open access archive for the deposit and dissemination of scientific research documents, whether they are published or not. The documents may come from teaching and research institutions in France or abroad, or from public or private research centers.
L'archive ouverte pluridisciplinaire HAL, est destinée au dépôt et à la diffusion de documents scientifiques de niveau recherche, publiés ou non, émanant des établissements d'enseignement et de recherche français ou étrangers, des laboratoires publics ou privés. 


\section{Title: Genomic and archaeological evidence suggest a dual origin of domestic dogs}

Authors: Laurent A. F. Frantz ${ }^{1 \dagger^{*}}$, Victoria E. Mullin ${ }^{2 \dagger}$, Maud Pionnier-Capitan ${ }^{3,4}$, Ophélie Lebrasseur $^{1}$, Morgane Ollivier ${ }^{3}$, Angela Perri ${ }^{5}$, Anna Linderholm ${ }^{1,6}$, Valeria Mattiangeli ${ }^{2}$, Matthew D. Teasdale ${ }^{2}$, Evangelos A. Dimopoulos ${ }^{1,7}$, Anne Tresset ${ }^{4}$, Marilyne Duffraisse ${ }^{3}$, Finbar McCormick $^{8}$, László Bartosiewicz ${ }^{9}$, Erika Gál ${ }^{10}$, Éva A. Nyerges ${ }^{10}$, Mikhail V. Sablin ${ }^{11}$, Stéphanie Bréhard ${ }^{4}$, Marjan Mashkour ${ }^{4}$, Adrian Bălășescu ${ }^{12}$, Benjamin Gillet ${ }^{3}$, Sandrine Hughes $^{3}$, Olivier Chassaing ${ }^{3}$, Christophe Hitte ${ }^{13}$, Jean-Denis Vigne ${ }^{4}$, Keith Dobney ${ }^{14}$, Catherine Hänni $^{3}$, Daniel G. Bradley ${ }^{2 *}$ and Greger Larson ${ }^{1 *}$

\section{Affiliations:}

${ }^{1}$ The Palaeogenomics \& Bio-Archaeology Research Network, Research Laboratory for Archaeology and History of Art, The University of Oxford, Oxford, UK.

${ }^{2}$ Smurfit Institute of Genetics, Trinity College Dublin, Dublin, Dublin 2, Ireland.

${ }^{3}$ CNRS/ENS de Lyon, IGFL, UMR 5242 and French National Platform of Paleogenetics, PALGENE, Ecole Normale Supérieure de Lyon, 46 allée d'Italie, 69364 Lyon Cedex 07, France / Université Grenoble Alpes, Laboratoire d'Ecologie Alpine (LECA), F-38000, Grenoble, France.

${ }^{4}$ CNRS/MNHN/SUs - UMR 7209, Archéozoologie et Archéobotanique, Sociétés, Pratiques et Environnements, Département Ecologie et Gestion de la Biodiversité, 55 rue Buffon, 75005 Paris, France.

${ }^{5}$ Department of Human Evolution, Max Planck Institute for Evolutionary Anthropology, 04103 Leipzig, Germany.

${ }^{6}$ Department of Anthropology, Texas A\&M University, College Station, TX 77843 4352, USA.

${ }^{7}$ School of Biology, Aristotle University of Thessaloniki, Thessaloniki, Greece.

${ }^{8}$ School of Geography, Archaeology and Palaeoecology, Queen's University Belfast, University Road, Belfast, Northern Ireland, UK.

${ }^{9}$ Osteoarchaeological Research Laboratory, University of Stockholm, Stockholm, Sweden.

${ }^{10}$ Archaeological Institute, Research Centre for the Humanities, Hungarian Academy of Sciences, Budapest, Hungary.

${ }^{11}$ Zoological Institute RAS, Universitetskaya nab. 1, 199034 Saint-Petersburg, Russia

12 The National Museum of Romanian History, 12 Calea Victoriei, 030026 Bucharest, Romania.

${ }^{13}$ Institut de Génétique et Développement de Rennes, CNRS-UMR6290, Université de Rennes 1, Rennes, France. 
${ }^{14}$ Department of Archaeology, School of Geosciences, University of Aberdeen,St. Mary's, Elphinstone Road, AB24 3UF, UK.

* Corresponding authors: Laurent A. F. Frantz - laurent.frantz@arch.ox.ac.uk; Greger

Larson - greger.larson@arch.ox.ac.uk; Dan G. Bradley - dbradley@tcd.ie

$\dagger$ Contributed equally

\begin{abstract}
The geographic and temporal origins of dogs remain controversial. Here, we generated genetic sequences from 59 ancient dogs and a complete (28x) genome of a late Neolithic dog $(\sim 4,800$ calBP) from Ireland. Our analyses revealed a deep split separating modern East Asian and Western Eurasian dogs. Surprisingly, the date of this divergence ( 14,000-6,400 years ago) occurs commensurate or several millennia after the first appearance of dogs in Europe and East Asia. Additional analyses of ancient and modern mitochondrial DNA revealed a sharp discontinuity in haplotype frequencies in Europe. Combined, these results suggest that dogs may have been domesticated independently in Eastern and Western Eurasia from distinct wolf populations. East Eurasia dogs were then possibly transported alongside people where they partially replaced European Palaeolithic dogs.
\end{abstract}

One Sentence Summary: Genomics and archaeology reveal both a possible dual origin of domestic dogs and a subsequent translocation of East Asian dogs into Europe.

Main Text: Dogs were the first domestic animal and the only animal domesticated prior to the advent of settled agriculture (1). Despite their importance in human history, no consensus has emerged with regard to their geographic and temporal origins, or whether dogs were domesticated just once or independently on more than one occasion. Though several claims have been made for an initial appearance of dogs in the early Upper Palaeolithic ( 30,000 years ago; e.g. 2), the first remains confidently assigned to dogs appear in Europe 15,000 years ago and in Far East Asia over 12,500 years ago $(1,3)$. While archaeologists remain open to the idea that there was more than one geographic origin for dogs $($ e.g. $(4,5)$, most genetic studies have concluded that dogs were likely domesticated just once $(6)$ - disagreeing on whether this occurred in Europe (7), Central Asia (8), or East Asia (9).

Recent palaeogenetic studies have had a tremendous impact on our understanding of early human evolution $($ e.g. $(10,11))$. Here we apply a similar approach to reconstruct the evolutionary history of dogs. We generated 59 ancient mtDNA sequences from European dogs (from 14,000 to 3,000 years ago) as well as a high coverage nuclear genome ( 28x) of an ancient $\operatorname{dog} \sim 4,800$ calBP (12) from the Neolithic passage grave complex of Newgrange (Sí an Bhrú) in Ireland. We combined our ancient sample with 80 modern publically available full genome sequences and 605 modern dogs (including village dogs and 48 breeds) genotyped on the 170k HD SNP array (12).

We first assessed characteristics of the Newgrange dog by typing SNPs associated with specific phenotypic traits and by inferring its level of inbreeding, compared to other breed and village dogs (12). Our results suggest that the degree of artificial selection and controlled breeding during the Neolithic was similar to that observed in modern free-living dogs. In addition, the Newgrange dog did not possess variants associated with modern breed-defining traits including hair length or coat color. And though this dog was likely able to digest starch less efficiently than modern dogs, it was more efficient than wolves (12). 
A phylogenetic analysis, based on 170k SNPs revealed a deep split separating the modern Sarloos breed from other dogs (Fig. 1a). This breed - created in the 1930s in the Netherlands involved breeding German Shepherds with captive wolves (13), thus explaining the breed's topological placement. Interestingly, the second deepest split (evident on the basis of both the 170K SNP panel - Fig 1a - and genome-wide SNPs - Fig. S4) separates modern East Asian and Western Eurasian (Europe and the Middle East) dogs. Moreover, the Newgrange dog clusters tightly with Western Eurasian dogs. We used Principal Component Analysis (PCA), D-statistics and TreeMix (12) to further test this pattern. Each of these analyses unequivocally placed the Newgrange dog with modern European dogs (Figs. S5, S6, S7). These findings demonstrate that the node separating the East Asian and Western Eurasian clades is older than the Newgrange individual; directly radiocarbon dated to $\sim 4,800$ years ago.

Other nodes leading to multiple dog populations and breeds (including the basal breeds (1) such as Greenland Sledge dogs or Siberian Husky; Fig. 1a) are poorly supported, suggesting that these breeds likely possess mixed ancestry from both Western Eurasian and East Asian dog lineages. To further assess the robustness of the deep split and those nodes associated with the potentially admixed lineages, we defined Western Eurasian and East Asian "core" groups (Fig. 1a) supported by the strength of the node leading to each cluster (12). We then used D-statistics to assess the affinity of each population to either Western Eurasian or East Asian core groups (12). The results of this analysis again revealed a clear East-West geographic pattern across Eurasia associated with the deep phylogenetic split (Fig. 1b). Breeds such as the Eurasier, Greenland Sledge dogs and Siberian Huskies (all basal breeds from Northern regions (1)), however, possess strong signatures of admixture with the East Asian core samples (Fig. S11), as do populations sampled in East Asia that clustered alongside Western Eurasian dogs (e.g. Papua New Guinean village dog; Fig. 1a).

We used the Multiple Sequentially Markovian Coalescent $(M S M C)(12,14)$ to reconstruct the population history of East Asian and Western Eurasia dogs. An analysis of individual high coverage genomes demonstrated a long, shared population history between the Newgrange dog and modern dogs from both Western Eurasia and East Asia (Fig. S15). A reconstruction using two genomes per group improved the resolution for recent time periods (Fig. 2a) and revealed a bottleneck in the Western Eurasian population, following its divergence from the East Asian core. A similar bottleneck observed in non-African human populations has been interpreted as a signature of a migration out of Africa (15). We therefore speculate that the analogous bottleneck observed in our dataset could be the result of a divergence and subsequent migration from east to west; supporting suggestions drawn from recent analyses of modern dog genomes $(8,9,16)$.

We then used MSMC to compute divergence times as a mean to assess the time frame of the shared population history among dogs, and between dogs and wolves. To obtain reliable time estimates, we used the radiocarbon age of the Newgrange dog to calibrate the mutation rate for dogs (12)(Fig. S16). This resulted in a mutation rate estimate of between $0.3 \times 10^{-8}$ and $0.45 \times 10^{-8}$ per generation - similar to that obtained with an ancient grey wolf genome (17). Using this mutation rate, we calculated the divergence time between the two modern Russian wolves (18) used in this study and the modern dogs to be 60,000-20,000 years ago (Fig. S17; Fig. 2b). Importantly, this date should not be interpreted as a time frame for domestication, since the wolves we examined may not have been closely related to the population that gave rise to dogs (6). 
These analyses also suggested that the divergence between the East Asian and Western Eurasian core groups ( 14,000-6,400 years ago) occurred commensurate, or several millennia after the earliest known appearance of domestic dogs in both Europe (>15,000 years) and East Asia (>12,500 years) (1) (Figs. S17, 2b). In addition, admixture signatures from wolves into Western Eurasian dogs most likely pushed this estimated time of divergence deeper into the past (12) meaning that the expected time of divergence between East and Western cores is likely younger than our estimate. These results imply that indigenous populations of dogs were already present in Europe and East Asia during the Palaeolithic (prior to this genomic divergence). Under this hypothesis, this early indigenous dog population in Europe was replaced (at least partially) by the arrival of East Eurasian dogs.

To investigate this potential replacement, we sequenced and analyzed 59 hyper-variable mtDNA fragments from ancient dogs spread across Europe and combined those with 167 modern sequences (12). Each sequence was then assigned to one of four major well-supported haplogroups (A-D) (19). While the majority of ancient European dogs belonged to either haplogroup C or D (63\% and 20\%, respectively), most modern European dogs possess sequences within haplogroups A and B (64 and 22\% respectively) (Fig. 2c, d, e). Using simulations, we showed that this finding cannot be explained by drift alone (12). Instead, this pattern arose from clear turnover in the mitochondrial ancestry of European dogs, most likely as a result of an arrival of East Asian dogs. This migration led to a partial replacement of ancient dog lineages in Europe that were present by at least 15,000 years ago (1).

Though the mtDNA turnover is obvious, the nuclear signature reveals an apparent longterm continuity. Assessments of ancestry in humans have demonstrated that major (nuclear) turnovers can be difficult to detect without samples from the admixing population (11). A genome-wide PCA analysis revealed that PC2 clearly discriminates the Newgrange dog from other modern dogs (Fig. S8), suggesting that this individual possessed ancestry from an unsampled population.

Our MSMC analysis reveals that the population split between the Newgrange dog and the East Asian core (as measured by cross coalescence rate [CCR]) is older (on average) than the split between modern Western Eurasian and East Asian lineages (Fig. 2b). Simulations suggest that this pattern could be explained by a partial replacement model in which the Newgrange dog retained a degree of ancestry from an outgroup population (Fig. S20a,b), that was different from modern wolves (12). Alternatively, this pattern could also be explained by secondary gene flow from Asian dogs into modern European dogs (Fig. S20c). Nevertheless, simulations show that secondary gene flow has a smaller effect on CCR than the partial replacement model (Fig. S20b,d). Moreover, secondary gene flow cannot explain the placement of the Newgrange dog on our genome-wide PCA (Fig. S8). Overall, these observations are consistent with a scenario in which the Newgrange dog retained a degree of ancestry from an ancient canid population that falls outside of the variation of modern dogs, but that is also different from modern wolves. This pattern also suggests that the replacement of European indigenous Palaeolithic dogs may not have been complete.

To assess the consilience between our results and the archaeological record, we compiled evidence for the earliest dog remains across Eurasia (Fig. 3a). We found that while dogs are present at sites as old as 12,500 years in Eastern Eurasia (China, Kamchatka and East Siberia) and 15,000 years in Western Eurasia (Europe and Near East) dog remains older than 8,000 years have yet to be recovered in Central Eurasia (Fig. 3a; Table S7). Combined with our DNA 
analyses, this observation suggests that two distinct populations of dogs were present in Eastern and Western Eurasia during the Palaeolithic.

The establishment of these populations is consistent with two scenarios: a single origin of Eurasian dogs followed by early transportation, founder effects, isolation and drift, or two independent domestication processes on either side of Eurasia. In the first scenario, the archaeological record should reveal a temporal cline of the first appearance of dogs across Eurasia stemming from a single source. Given the current lack of dog remains prior to 8,000 years ago in Central Eurasia, a scenario involving a single origin followed by an early transportation seems less likely.

Given our combined results, we suggest the following hypothesis: two genetically differentiated and potentially extinct wolf populations in Eastern $(8,9)$ and Western Eurasia $(7)$ may have been independently domesticated prior to the advent of settled agriculture (Fig. 3a). The eastern dog population then dispersed westward alongside humans, between 6,400 and 14,000 years ago, into Western Europe $(10,11,20)$ whereupon they partially replaced an indigenous Palaeolithic dog population. Our hypothesis reconciles previous studies that have suggested domestic dogs originated in East Asia $(9,19)$ and Europe (7). For numerous reasons, the null hypothesis should be that individual animal species were domesticated just once (21). The combined genetic and archaeological results presented here, however, suggest that dogs, like pigs (22), may have been domesticated twice. Nevertheless, given the complexity of the evolutionary history of dogs and uncertainties related to mutation rates, generation times and the incomplete nature of the archaeological record, our scenario remains hypothetical. Genome sequences derived from ancient Eurasian dogs and wolves will provide the necessary means to assess whether dog domestication occurred more than once.

\section{References and Notes:}

1. G. Larson et al., Proc. Natl. Acad. Sci. 109, 8878-83 (2012).

2. M. Germonpré, M. Lázničková-Galetová, M. V. Sablin, J. Archaeol. Sci. 39, 184-202 (2012).

3. M. Pionnier-Capitan et al., J. Archaeol. Sci. 38, 2123-2140 (2011).

4. T. Dayan, J. Archaeol. Sci. 21, 633-640 (1994).

5. M. Ollivier et al., PLoS One. 8, e75110 (2013).

6. A. H. Freedman et al., PLoS Genet. 10, e1004016 (2014).

7. O. Thalmann et al., Science. 342, 871-4 (2013).

8. $\quad$ L. M. Shannon et al., Proc. Natl. Acad. Sci. U. S. A. 112, 13639-13644 (2015).

9. G.-D. Wang et al., Cell Res. 26, 21-33 (2015).

10. M. E. Allentoft et al., Nature. 522, 167-172 (2015).

11. W. Haak et al., Nature. 522, 207-211 (2015).

12. Supplementary Material.

13. D. Morris, Dogs: The Ultimate Dictionary of Over 1,000 Dog Breeds (Trafalgar Square, 2008). 
14. S. Schiffels, R. Durbin, Nat. Genet. 46, 919-25 (2014).

15. H. Li, R. Durbin, Nature. 475, 493-6 (2011).

16. M. Pilot et al., Proc. Biol. Sci. 282, 20152189- (2015).

17. P. Skoglund, E. Ersmark, E. Palkopoulou, L. Dalén, Curr. Biol. 25, 1515-1519 (2015).

18. G. Wang et al., Nat. Commun. 4, 1860 (2013).

19. P. Savolainen, Y. Zhang, J. Luo, J. Lundeberg, T. Leitner, Science. 298, 1610-3 (2002).

20. L. M. Cassidy et al., Proc. Natl. Acad. Sci. 113, 201518445 (2015).

21. G. Larson, J. Burger, Trends Genet. 29, 197-205 (2013).

22. L. A. F. Frantz et al., Nat. Genet. 47, 1141-1148 (2015).

23. C. Gamba et al., Nat. Commun. 5, 5257 (2014).

24. L. H. van Wijngaarden-Bakker, Proc. R. Irish Acad. Sect. C Archaeol. Celt. Stud. Hist. Linguist. Lit. 86C, 17-111 (1986).

25. M. J. O'Kelly, R. M. Cleary, D. Lehane, Newgrange, Co. Meath, Ireland: The Late Neolithic/Beaker Period Settlement (B.A.R., 1983).

26. F. McCormick, in The Holocene History of the European Vertebrate Fauna: Modem Aspects of Research, N. Benecke, Ed. (1998).

27. P. Reimer, Radiocarbon. 55, 1869-1887 (2013).

28. S. Pääbo et al., Annu. Rev. Genet. 38, 645-679 (2004).

29. L. Orlando et al., Genome Res. 21, 1705-19 (2011).

30. J. T. Vilstrup et al., PLoS One. 8, e55950 (2013).

31. M. Meyer, M. Kircher, Cold Spring Harb. Protoc. 2010, pdb.prot5448 (2010).

32. M. Martin, EMBnet.journal. 17, 10 (2011).

33. H. Li, R. Durbin, Bioinformatics. 25, 1754-60 (2009).

34. K. Lindblad-Toh et al., Nature. 438, 803-19 (2005).

35. M. Schubert et al., Nat. Protoc. 9, 1056-82 (2014).

36. H. Li et al., Bioinformatics. 25, 2078-9 (2009).

37. A. McKenna et al., Genome Res. 20, 1297-1303 (2010).

38. K. Okonechnikov, A. Conesa, F. García-Alcalde, Bioinformatics. 32, 292-4 (2015).

39. H. Jónsson, A. Ginolhac, M. Schubert, P. L. F. Johnson, L. Orlando, Bioinformatics. 29, 1682-4 (2013).

40. B. Bai et al., Nucleic Acids Res. 43, 777-83 (2014).

41. A. Auton et al., Science. 336, 193-8 (2012).

42. A. R. Quinlan, I. M. Hall, Bioinformatics. 26, 841-2 (2010).

43. E. Han, J. S. Sinsheimer, J. Novembre, Mol. Biol. Evol. 31, 723-35 (2014). 
44. A. Vaysse et al., PLoS Genet. 7, e1002316 (2011).

45. M. L. Speir et al., Nucleic Acids Res., 44 717-25 (2016).

46. S. Purcell et al., Am. J. Hum. Genet. 81, 559-75 (2007).

47. E. Paradis, J. Claude, K. Strimmer, Bioinformatics. 20, 289-290 (2004).

48. N. Patterson, A. L. Price, D. Reich, PLoS Genet. 2, e190 (2006).

49. J. K. Pickrell, J. K. Pritchard, PLoS Genet. 8, e1002967 (2012).

50. E. Y. Durand, N. Patterson, D. Reich, M. Slatkin, Mol. Biol. Evol. 28, 2239-2252 (2011).

51. N. Patterson et al., Genetics. 192, 1065-93 (2012).

52. S. R. Browning, B. L. Browning, Am. J. Hum. Genet. 81, 1084-97 (2007).

53. Z. Fan et al., Genome Res. 26, 163-73 (2016).

54. H. Angleby, P. Savolainen, Forensic Sci. Int. 154, 99-110 (2005).

55. A. Ardalan et al., Ecol. Evol. 1, 373-85 (2011).

56. A. R. Boyko et al., Proc. Natl. Acad. Sci. U. S. A. 106, 13903-8 (2009).

57. S. K. Brown et al., PLoS One. 6, e28496 (2011).

58. S. Castroviejo-Fisher, P. Skoglund, R. Valadez, C. Vilà, J. A. Leonard, BMC Evol. Biol. 11, 73 (2011).

59. V. Muñoz-Fuentes, C. T. Darimont, P. C. Paquet, J. A. Leonard, Conserv. Genet. 11, 547556 (2009).

60. N. Okumura, N. Ishiguro, M. Nakano, A. Matsui, M. Sahara, Anim. Genet. 27, 397-405 (2009).

61. M. C. R. Oskarsson et al., Proc. Biol. Sci. 279, 967-74 (2012).

62. J.-F. Pang et al., Mol. Biol. Evol. 26, 2849-64 (2009).

63. P. Savolainen, T. Leitner, A. N. Wilton, E. Matisoo-Smith, J. Lundeberg, Proc. Natl. Acad. Sci. U. S. A. 101, 12387-90 (2004).

64. K. Tsuda, Y. Kikkawa, H. Yonekawa, Y. Tanabe, Genes Genet. Syst. 72, 229-38 (1997).

65. J. A. Leonard et al., Science. 298, 1613-6 (2002).

66. M. F. Deguilloux, J. Moquel, M. H. Pemonge, G. Colombeau, J. Archaeol. Sci. 36, 513519 (2009).

67. F. Verginelli et al., Mol. Biol. Evol. 22, 2541-51 (2005).

68. M. Pionnier-Capitan, thesis, ENS Lyon (2010).

69. O. Lebrasseur, thesis, Durham University (2014).

70. N. Rohland, M. Hofreiter, Nat. Protoc. 2, 1756-62 (2007).

71. A. Cooper, Science (80-. ). 289, 1139b-1139 (2000).

72. M. T. P. Gilbert, H.-J. Bandelt, M. Hofreiter, I. Barnes, Trends Ecol. Evol. 20, 541-4 
(2005).

73. K. S. Kim, S. E. Lee, H. W. Jeong, J. H. Ha, Mol. Phylogenet. Evol. 10, 210-20 (1998).

74. M.-S. Peng et al., Mol. Ecol. Resour. 15, 1238-42 (2015).

75. R. C. Edgar, Nucleic Acids Res. 32, 1792-7 (2004).

76. J. Leigh, PopART (Population Analysis with Reticulate Trees) (2015).

77. R. R. Hudson, Bioinformatics. 18, 337-338 (2002).

78. G. K. Chen, P. Marjoram, J. D. Wall, Genome Res. 19, 136-42 (2009).

79. D. H. Alexander, J. Novembre, K. Lange, Genome Res. 19, 1655-64 (2009).

80. M. Boudadi-Maligne, J.-B. Mallye, M. Langlais, C. Barshay-Szmidt, PALEO, 39-54 (2012).

81. R. J. Losey et al., PLoS One. 8, e63740 (2013).

82. N. Benecke, J. Archaeol. Sci. 14, 31-49 (1987).

83. M. Germonpré et al., J. Archaeol. Sci. 36, 473-490 (2009).

84. R. Flad, J. East Asian Archaeol. 3, 23-51 (2001).

85. L. Barton et al., Proc. Natl. Acad. Sci. U. S. A. 106, 5523-8 (2009).

86. A. Lasota-Moskalewska, K. Szymczak, M. Khudzhanazarov, Archaeol. Balt. 11 (2009).

87. A. Razzokov. Sarazm. Dushanbe: Institute of History, Archaeology, and Ethnography. Dushanbe, Tajikistan: Academy of Sciences of Tajikistan A. Donish History, Archaeology and Ethnographic Institute. (2008).

88. H. Bocherens, M. Mashkour, D. Billiou, Environ. Archaeol. 33, 253-64 (2013).

89. A. K. Kasparov, Paléorient. 22, 161-167 (1996).

90. M. Frachetti, N. Benecke, Antiquity. 83, 1023-1037 (2015).

91. C. Chang, N. Benecke, F. Grigoriev, A. Rosen, P. Tourtellotte, Antiquity. 77, 298-312 (2003)

92. V. Bakhshaliev, in The Archaeology of Nakhichevan. Ten Years of New Discoveries (Ege Yayinlari, Istanbul, 1997).

93. R. Berthon et al., Environ. Archaeol. 18, 191-200 (2013).

94. S. J. Pawankar and P. K. Thomas, Bulletin of the Deccan College Research Institute 56, 363-370 (1996).

95. B. \& R. Allchin, F. R. Allchin, in The Birth of Indian Civilization: India and Pakistan Before 500 B.C. (1968).

96. R. V. Joshi, Archaeol. Surv. India, New Delhi, India, 12-16 (1961).

97. P. K. Thomas, in The Walking larder: patterns of domestication, pastoralism, and predation (Routledge, 2014).

98. B. P. Sahu, From hunters to breeders: faunal background of early India (Anamika 
Prakashan, 1988).

99. N. Bhola, G. V. S. Rao, Animal remains from Lothal excavations (Zoological Survey of India, 1962).

100. R. B. . Sewell, B. S. Guha, in Mohenjo-Daro and the Indus (1931).

101. G. Stein, in Early Animal Domestication and Its Cultural Context, P. J. Crabtree, D. V. Campana, K. Ryan, Eds. (UPenn Museum of Archaeology, 1989).

102. Telegin D.Ya., redno-Stogivska kultura epokhi midi. (1973).

103. K. N. Wilkinson et al., J. F. Archaeol. 37, 20-33 (2013).

104. R. D. Barnett, W. Watson, Iraq. 14, 132 (1952).

105. M. D. Frachetti, N. Benecke, A. N. Mar’yashev, P. N. Doumani, World Archaeol. 42, 622-646 (2010).

106. P. M. Dolukhanov, in Hunters in transition: Mesolithic societies of temperate Eurasia and their transition to farming (1986).

107. G. Matyushin, The mesolithic and neolithic in the southern Urals and central Asia. (1986).

108. N. D. Ovodov et al., PLoS One. 6, e22821 (2011).

109. M. Germonpré, M. Lázničková-Galetová, R. J. Losey, J. Räikkönen, M. V. Sablin, Quat. Int. 359-360, 261-279 (2015).

110. M.-A. Garcia, Bull. la Société préhistorique française. 102, 103-108 (2005).

111. M. V. Sablin, G. A. Khlopachev, Curr. Anthropol. 43, 795-799 (2002).

112. A. Perri, J. Archaeol. Sci. 68, 1-4 (2016).

113. S. J. Crockford, Y. V. Kuzmin, J. Archaeol. Sci. 39, 2797-2801 (2012).

114. M. Boudadi-Maligne, G. Escarguel, J. Archaeol. Sci. 45, 80-89 (2014).

115. A. G. Drake, M. Coquerelle, G. Colombeau, Sci. Rep. 5, 8299 (2015).

116. D. P. Howrigan, M. A. Simonson, M. C. Keller, BMC Genomics. 12, 460 (2011).

117. E. Axelsson et al., Nature. 495, 360-4 (2013).

118. E. Cadieu et al., Science. 326, 150-3 (2009).

119. H. G. Parker et al., Science. 325, 995-8 (2009).

Acknowledgments: Raw reads of the Newgrange dog have been deposited at the European Nucleotide Archive (ENA) with project number: PRJEB13070. Mitochondrial sequences as well as genotype files (in plink format) were deposited on Dryad

(http://datadryad.org/review?doi=doi:10.5061/dryad.8gp06). We would like to thank G. Wang, J. Schraiber, L. Orlando, L. Dalén, R.E. Green, P. Savolainen, E. Loftus for their valuable input. We are also grateful to A. Osztás and I. Zalai-Gaál R.-M. Arbogast, A. Beeching, A. Boroneant, O. Lecomte, S. Madeleine, C. \& D. Mordant, M. Patou-Mathis, P. Pétrequin, L. Salanova, J. Schibler, A. Tsuneki, F. Valla for providing archaeological material. L.A.F.F., O.L., A.L. and 
G.L. were supported by a European Research Council grant (ERC-2013-StG-337574-UNDEAD) and Natural Environmental Research Council grants (NE/K005243/1 and NE/K003259/1). L.A.F.F. was supported by a Junior Research Fellowship (Wolfson College, University of Oxford). V.E.M, V.M , M.D.T. and the sequencing of the Newgrange dog genome were funded by ERC Investigator grant 295729-CodeX awarded to D.G.B. We would also like to acknowledge the National Museum of Ireland for providing the petrous bone of the Newgrange dog and the Science Foundation Ireland Award 12/ERC/B2227 and Trinseq. AB was supported by a Romanian National Authority for Scientific Research (PN-II-ID-PCE-2011-3-1015). The work at ENS Lyon and at MNHN Paris was also supported by PURINA-NESTLE. The authors declare no conflict of interest.

Fig. 1: Deep split between East Asian and Western Eurasian dogs.a. A neighbour-joining tree (with bootstrap values) based on Identity by State (12) of 605 dogs. Red and yellow clades represent the East Asian and Western Asian core groups respectively (12). b. A map showing the location and relative proportion of ancestry (mean D-values) of dogs (Fig. S10). Positive values (red) indicate that the population shares more derived alleles with the East Asian core while negative values (yellow) indicate a closer association with the Western Eurasian core.

Fig. 2: Effective population size, divergence times and mtDNA. $a$. Effective population size through time of East and Western Eurasian dogs and wolves with MSMC. $\boldsymbol{b}$. Cross-coalescence rate (CCR) per year for each population pair in Fig. 2a. The CCR represents the ratio of within and between population coalescence rates (CR). The ratio measures the age and pace of divergence between two populations. Values close to 1 indicate that both within and between CR are equal meaning the two populations have not yet diverged. Values close to 0 indicate that the populations have completely diverged. $\boldsymbol{c}$. Bar plot representing the proportion of mtDNA haplogroups at different time periods. $\boldsymbol{d}$. Locations of archaeological sites with haplogroup proportions. $\boldsymbol{e}$. Location of modern samples with haplogroup proportions.

Fig. 3: Archaeological evidence for the first appearance of dogs across Eurasia and a model of dog domestication. $a$. Map representing the geographic origin and age of the oldest archaeological dog remains in Eurasia (12). b. A suggested model of dog domestication under the dual origin hypothesis. An initial wolf population split into East and West Eurasian wolves that were then domesticated independently before going extinct (as indicated by the $\uparrow$ symbol). The Western Eurasian dog population (European) was then partially replaced by a humanmediated translocation of Asian dogs at least 6,400 years ago, a process that took place gradually after the arrival of the eastern dog population.

\section{Supplementary Materials:}

Materials and Methods

Figs. S1-S29

Tables S1-S7

References (23-110) 